\title{
Cardiopulmonary Exercise Test in Leukemia Patients After Chemotherapy: A Feasibility Study
}

\author{
Soojae Kim, $\mathrm{MD}^{1}$, Ik-Chan Song, $\mathrm{MD}^{2}$, Sungju Jee, $\mathrm{MD}, \mathrm{PhD}^{1}$
}

Departments of ${ }^{1}$ Rehabilitation Medicine and ${ }^{2}$ Internal Medicine, Chungnam National University Hospital, Daejeon, Korea

\begin{abstract}
Objective To explore the feasibility of cardiopulmonary exercise test (CPET) in leukemia patients after chemotherapy. Methods Leukemia patients with histologically confirmed hematologic malignancies were reviewed. We evaluated for CPET, between receiving chemotherapy and undergoing stem cell transplantation after 2 weeks. We recorded exercise testing and physiologic parameters during CPET between January 2013 to May 2015. All patients were subjected to symptoms limited to exercise testing, according to the Modified Bruce Protocol. We considered that if respiratory exchange ratio achieved was over 1.10, participants had successfully completed CPET. We dichotomized all participants into two groups (normal group, normal range of resting heart rate; higher group, over 100 per minute of heart rate).

Results 30 patients were finally enrolled. All participants had no adverse effects during the exercise test. Mean peak double product was $26,998.60 \mathrm{mmHg}$.beats/min (range, 15,481-41,004), and mean peak oxygen consumption $\left(\mathrm{VO}_{2}\right.$ peak) was $22.52 \pm 4.56 \mathrm{~mL} / \mathrm{kg} / \mathrm{min}$. Significant differences were observed in the normal group with $\mathrm{VO}_{2}$ peak (mean, $24.21 \mathrm{~mL} / \mathrm{kg} / \mathrm{min} ; \mathrm{p}=0.027$ ) and number of prior intensive chemotherapy, compared to the higher group (mean, 1.95 ; $\mathrm{p}=0.006$ ).

Conclusion Our results indicate that CPET in leukemia patients before stem cell transplantation was very safe, and is an efficient method to screen for patients with poor cardiac functions. As CPET presents the parameters which reveal the cardiopulmonary functions, including $\mathrm{VO}_{2}$ peak, double product and exercise capacity, this exercise test would help to predict the physical performance or general condition of the leukemia patients.
\end{abstract}

Keywords Exercise test, Leukemia, Feasibility studies, Rehabilitation, Tachycardia

\section{INTRODUCTION}

Myeloablative conditioning followed by allogeneic stem cell transplantation (allo-SCT), is the only therapy in many cases, contributing to long-term survival for high-risk or relapsed hematologic malignancies. Nevertheless, these procedures are associated with substantial morbidity and an $18 \%-46 \%$ risk of 1 -year non-relapse mortality [1-4]. The incidence of pulmonary toxicity, including interstitial pneumonitis, infectious pneumonia,

Received February 16, 2016; Accepted August 24, 2016

Corresponding author: Sungju Jee

Department of Rehabilitation Medicine, Chungnam National University Hospital, 282 Munhwa-ro, Jung-gu, Daejeon 35015, Korea. Tel: +82-42-3382460, Fax: +82-42-338-2461, E-mail: drjeesungju@hanmail.net

ORCID: Soojae Kim (http://orcid.org/0000-0002-2681-4825); Ik-Chan Song (http://orcid.org/0000-0002-6938-970X); Sungju Jee (http://orcid. org/0000-0002-9400-9609).

(c) This is an open-access article distributed under the terms of the Creative Commons Attribution Non-Commercial License (http://creativecommons.org/ licenses/by-nc/4.0) which permits unrestricted noncommercial use, distribution, and reproduction in any medium, provided the original work is properly cited. Copyright (c) 2017 by Korean Academy of Rehabilitation Medicine 
diffuse alveolar hemorrhage, obstructive bronchiolitis and respiratory failure requiring ventilatory support, is particularly prevalent following myeloablative conditioning regimens [5-9]. Thus, investigating patients at highest risk of transplant-related complications, is of major clinical importance.

In recent years, several studies indicate that cardiopulmonary exercise test (CPET) is a safe and feasible tool providing an objective assessment of the exercise capacity in specific cancer patients, such as lung cancer, breast cancer and glioma [10-13]. In addition, these studies demonstrate that cancer patients have significant reductions in peak (for example, peak oxygen consumption $\left[\mathrm{VO}_{2}\right.$ peak]) and sub-maximal (for example, ventilatory threshold, minute ventilation-carbon dioxide production relationship) measures of cardiopulmonary function (also commonly referred to as exercise capacity) across the entire survivorship [11-13].

During the past several decades, clinical investigators attempted to enhance the ability of the standard exercise test to predict future cardiovascular events, by identifying variables with the highest prognostic power. In particular, hemodynamic information, including heart rate (HR), blood pressure (BP), and exercise capacity, were important features of the exercise test [14-16]. To consider the prognostic values of both $\mathrm{HR}$ and $\mathrm{BP}$, it was proposed to use the product of $\mathrm{HR}$ and systolic $\mathrm{BP}$, generally defined as the double product. Double product was directly proportional to the work performed by the heart, and is considered an indirect indicator of myocardial oxygen uptake, as well as an index to evaluate the response of coronary circulation to the metabolic demand, in normal participants and in patients with ischemic heart disease [17-20].

Against this background, we conducted this study to evaluate the feasibility and safety of symptom-limited CPET in patients with high-risk or relapsed hematologic malignancies, such as acute myeloid leukemia, acute lymphoblastic leukemia, and myelodysplastic syndrome, after delivery of conventional chemotherapy. We also investigated whether these parameters provide any additional information of the functional status, beyond traditional markers (e.g., age, gender) in this population.

\section{MATERIALS AND METHODS}

\section{Study participants and setting}

Patients with histologically confirmed hematologic malignancies, undergoing chemotherapy conditioning followed by allo-SCT, were retrospectively recruited. Additional eligibility criteria included (1) chemotherapy responsive disease, (2) age (>18 years old), (3) Eastern Cooperative Oncology Group (ECOG) performance status of 0 or 1, (4) primary attending oncologist approval, (5) ability to read and understand language, and (6) no contraindications to a maximal CPET as per American Thoracic Society recommendations. The examples of contraindications were syncope, room air desaturation $(<85 \%)$, respiratory failure, mental impairment leading to inability to cooperate absolutely, severe untreated arterial hypertension at rest $(>200 \mathrm{mmHg}$ systolic, $>120 \mathrm{mmHg}$ diastolic), arrhythmia, electrolyte abnormalities, and orthopedic impairments that compromise exercise performance in relatively [21]. All patients completed a standard pretransplant work-up prior to registration, involving complete history and physical examination including oxygen saturation, ECOG performance status, and resting $\mathrm{FEV}_{1}$. All patients were examined by CPET after receiving chemotherapy, followed by allo-SCT 2 weeks later. We dichotomized all participants into two groups-normal group, normal range of HR; higher group, over 100 per minute (tachycardia) of HR-by using a resting HR.

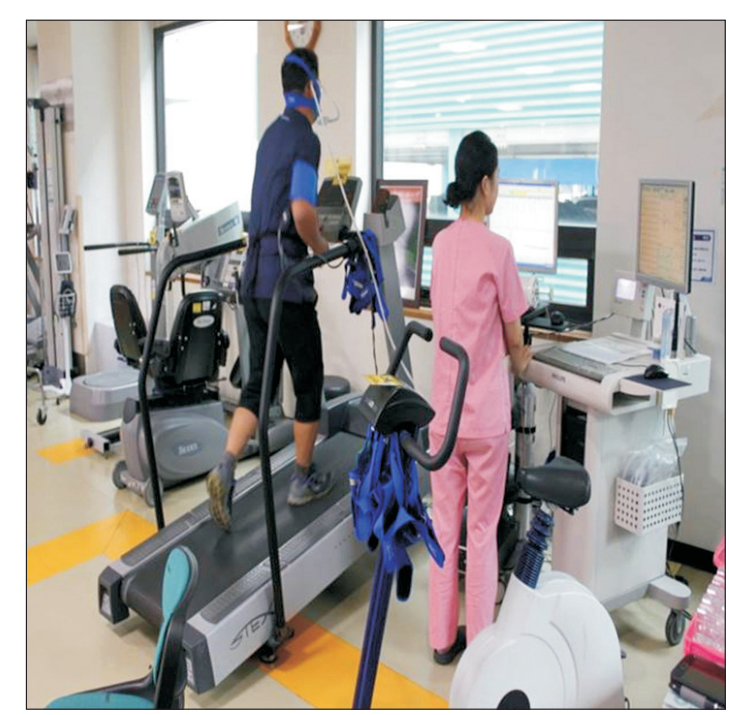

Fig. 1. Cardiopulmonary exercise test facilities with 12lead ECG monitoring (ST80i Stress Testing System, Philips Medical System, Andover, MA,USA). 


\section{Incremental CPET}

To determine peak and sub-maximal markers of exercise capacity, a CPET with 12-lead ECG monitoring (ST80i Stress Testing System; Philips Medical System, Andover, MA, USA) (Fig. 1) was performed by a specialist nurse, prior to initiation of the myeloablative conditioning regimen, according to CPET guidelines for clinical populations. All tests were performed on a respiratory desktop diagnostics and automatic treadmill with breathby-breath expired gas analysis (Ultima Desktop Diagnostics; Medical Graphics Corp., Saint Paul, MN, USA). All patients were subjected to symptoms limited exercise testing, according to the Modified Bruce Protocol. If respiratory exchange ratio was achieved at over 1.10, we considered that participants were examined at their peak effort, and were successful in concluding the CPET. Workloads were consecutively increased as follows, each lasting 3 minutes. The 1 st was at $1.7 \mathrm{mph}$ and a $0 \%$ grade, the 2 nd was at $1.7 \mathrm{mph}$ and a $5 \%$ grade, and the 3rd stage corresponded to the 1st stage of the standard Bruce Test protocol. $\mathrm{VO}_{2}$ peak was defined as the highest $\mathrm{VO}_{2}$ value for a given 15-second interval within the last 60 seconds of exercise, and ventilatory threshold was calculated using standard methods [22]. Age-matched normative peak $\mathrm{VO}_{2}$ data for healthy individuals without a history of cancer was calculated from the equations provided by Fitzgerald et al. [23] (women) and Wilson and Tanaka [24] (men), respectively. We calculated the predicted percentage of $\mathrm{VO}_{2}$ peaks for either men or women, according to the following equation: measured value per normal agematched reference value $[23,24]$. During submaximal exercise test and during the recovery period, BP was assessed by advancing the next stage of the Modified Bruce Protocol. Double product was obtained by multiplying systolic BP and HR for the same time period. We also executed in body composition measurements (total body weight, lean body mass, fat mass, and skeletal muscle mass in upper or lower extremities) for participants, using multi-frequency bioelectrical impedance analysis with eight-point tactile electrodes (InBody 720; Biospace, Tokyo, Japan).

\section{Myeloablative conditioning regimens}

All patients received total body irradiation (TBI) with two conditioning regimens. One was TBI with fludarabine (120-180 mg/m², plus busulfan, $\leq 8 \mathrm{mg} / \mathrm{kg}$ orally or $6.4 \mathrm{mg} / \mathrm{kg}$ intravenously; Bu4-Flu), and the other was TBI with reduced intensity fludarabine $\left(120-180 \mathrm{mg} / \mathrm{m}^{2}\right.$, plus busulfan, $16 \mathrm{mg} / \mathrm{kg}$ orally or $12.8 \mathrm{mg} / \mathrm{kg}$ intravenously; Bu2-Flu), depending on the underlying disease.

\section{Clinical parameters and safety}

Medical characteristics were extracted from medical records. Performance status was assessed using the ECOG at the time of consultation for examination. For safety, we conducted an examination of all vital signs of the patients, including BP, HR, respiratory rate and electrocardiography, after doing CPET once. We were also vigilant to check for falls, since this could be a dangerous problem during walking or running on the treadmill lane.

\section{Statistical analysis}

All numerical parameters were expressed as the mean \pm standard deviation. The Mann-Whitney test for numerical non-parametric features was used for examining the differences between the two defined groups. The Fisher exact test for proportional non-parametric features was used for examining the differences between the two defined groups.

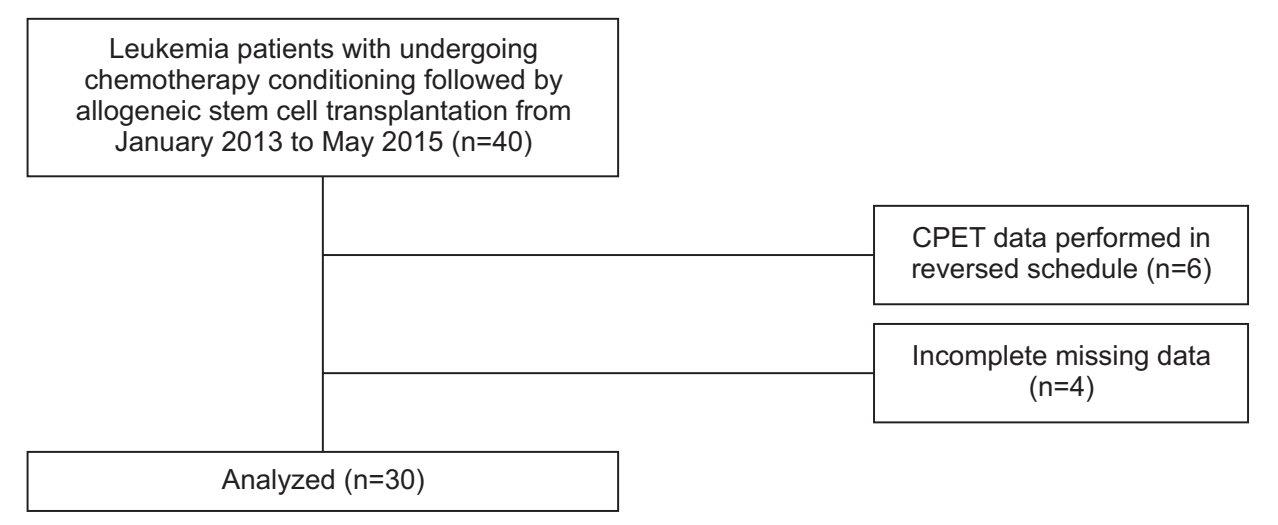

Fig. 2. Flow chart for determining study participants. CPET, cardiopulmonary exercise test. 


\section{RESULTS}

\section{Baseline demographics}

Participants were recruited between January 2013 to May 2015. Initially, 40 patients with leukemia were enrolled; however, 6 patients were excluded by the CPET data performed in reversed schedule (testing date prior to the chemotherapy duration), and 4 patients had incomplete CPET due to missing data, including resting BP or resting HR. The number of participants finally evaluated was 30 (Fig. 2). The demographics of all participants are presented in Table 1. The majority of patients were male $(66.7 \%)$, while the mean age was $50.97 \pm 12.81$ years (range, 18-66 years). The number of chemotherapy courses prior to the conditioning regimen was 2 (range, $0-12)$. ECOG performance status was 0 (50\%), 1 (46.7\%) or $2(0.3 \%)$. The conditioning regimen of chemotherapy were myeloablating (Bu4-Flu), reduced intensity (Bu2Flu), and not done, in $66.7 \%, 23.3 \%$, and $10.0 \%$, respectively.

\section{Feasibility of incremental exercise testing}

All patients successfully completed all testing procedures. All CPETs were considered to be of 'peak' effort, given that a respiratory exchange ratio over 1.10 was achieved. No serious adverse events were observed during CPET procedures. All patients subsequently completed the prescribed conditioning regimen followed by alloSCT, as scheduled.

\section{Peak and submaximal cardiovascular function and functional capacity}

For the overall sample, mean of $\mathrm{VO}_{2}$ peak was $22.89 \pm$ $4.69 \mathrm{~mL} / \mathrm{kg} / \mathrm{min}$ (range, $11.00-32.00 \mathrm{~mL} / \mathrm{kg} / \mathrm{min}$ ). Mean $\mathrm{VO}_{2}$ peak was $24.08 \pm 4.28 \mathrm{~mL} / \mathrm{kg} / \mathrm{min}$ in patients with ECOG $0(\mathrm{n}=15), 21.65 \pm 4.03 \mathrm{~mL} / \mathrm{kg} / \mathrm{min}$ for ECOGl $(\mathrm{n}=12)$, and $11.7 \mathrm{~mL} / \mathrm{kg} / \mathrm{min}$ for ECOG $2(\mathrm{n}=1)$. After division of groups considering the resting HR, we found that the number of chemotherapy courses prior to the conditioning regimen and the $\mathrm{VO}_{2}$ peak were significantly associated with the difference of a resting HR (Table 2). Each mean of the number of chemotherapy courses prior to the conditioning regimen was $1.95 \pm 1.10$ in normal group, and 4.20 \pm 3.01 in the higher group ( $\mathrm{p}=0.006$ ) (Fig. 3). The mean of $\mathrm{VO}_{2}$ peak were $24.21 \pm 4.00 \mathrm{~mL} / \mathrm{kg} / \mathrm{min}$ in the normal group, and $20.25 \pm 5.04 \mathrm{~mL} / \mathrm{kg} / \mathrm{min}$ in the higher
Table 1. Baseline characteristics of patients $(n=30)$

\begin{tabular}{|c|c|}
\hline Characteristic & $\begin{array}{c}\text { No. of patients } \\
(\%)\end{array}$ \\
\hline Age (yr), median (range) & $55.5(18-66)$ \\
\hline \multicolumn{2}{|l|}{ Gender } \\
\hline Male & $20(66.7)$ \\
\hline Female & $10(33.3)$ \\
\hline \multicolumn{2}{|l|}{ Disease type } \\
\hline AML & $23(76.7)$ \\
\hline ALL & $4(13.3)$ \\
\hline MDS & $3(10.0)$ \\
\hline $\begin{array}{l}\text { Number of prior chemotherapy cycles } \\
\text { (range) }\end{array}$ & $2(0-12)$ \\
\hline \multicolumn{2}{|l|}{ Disease status } \\
\hline 1st CR & $23(76.7)$ \\
\hline 2nd CR & $4(13.3)$ \\
\hline MDS & $3(10.0)$ \\
\hline $\begin{array}{l}\text { Poor risk group (poor cytogenetics \& } \\
\text { secondary AML) }\end{array}$ & $16(53.3)$ \\
\hline \multicolumn{2}{|l|}{ ECOG performance status } \\
\hline 0 & $15(50.0)$ \\
\hline 1 & $14(46.7)$ \\
\hline 2 & $1(3.3)$ \\
\hline \multicolumn{2}{|l|}{ HCT comorbidity index } \\
\hline 0 & $17(56.7)$ \\
\hline 1 & $7(23.3)$ \\
\hline 2 & $3(10.0)$ \\
\hline 3 & $3(10.0)$ \\
\hline \multicolumn{2}{|l|}{ Donor } \\
\hline Sibling & $15(50.0)$ \\
\hline Familial mismatched & $3(10.0)$ \\
\hline Unrelated & $8(26.7)$ \\
\hline Cord & $1(3.3)$ \\
\hline Not done & $3(10.0)$ \\
\hline \multicolumn{2}{|l|}{ Stem cell source } \\
\hline Peripheral blood & $26(86.7)$ \\
\hline Cord & $1(3.3)$ \\
\hline Not done & $3(10.0)$ \\
\hline \multicolumn{2}{|l|}{ Conditioning regimens } \\
\hline Myeloablating (Bu4-Flu) & $20(66.7)$ \\
\hline Reduced intensity (Bu2-Flu) & $7(23.3)$ \\
\hline Not done & $3(10.0)$ \\
\hline
\end{tabular}

AML, acute myeloid leukemia; ALL, acute lymphoblastic leukemia; MDS, myelodysplastic syndrome; CR, complete remission; ECOG, Eastern Cooperative Oncology Group; HCT, hematopoietic cell transplant. 
group ( $\mathrm{p}=0.027$ ) (Fig. 4). Other predicted factors, including resting or peak double product and lean body mass, were not significantly associated with a resting HR (peak double product 26,688.55 $\pm 6,929.30 \mathrm{mmHg}$.beats/ min vs. $26,012.60 \pm 5,084.15 \mathrm{mmHg}$.beats $/ \mathrm{min} ; \mathrm{p}=0.713$ ), lean body mass $(47.88 \pm 10.49 \mathrm{~kg}$ vs. $41.04 \pm 10.37 \mathrm{~kg}$; $\mathrm{p}=$ $0.067)$, and resting double product $(11,125.20 \pm 1,868.80$ $\mathrm{mmHg}$.beats/min vs. $12,476.90 \pm 1,946.69 \mathrm{mmHg} \cdot$ beats/ $\min ; \mathrm{p}=0.067$ ).

\section{Pulmonary or cardiac toxicity and safety}

None of the participants developed any other complications, including pulmonary or cardiac toxicity, after conclusion of CPET. All vitals of patients, including BP, $\mathrm{HR}$, respiratory rate and electrocardiography, were entirely non-specific, with all results in the normal range.

\section{DISCUSSION}

In this study, we successfully conducted CPET of all participants, and found that CPET was a feasible and safe procedure to provide an objective measure of exercise capacity in patients with high-risk or relapsed hematologic malignancies. This was an important finding since CPET procedures require exercise to symptom limitation. Furthermore, CPET was performed within a 'high-risk' window between completion of conventional chemotherapy and initiation of the conditioning regimen of high-dose chemotherapy. However, 'high risk' is not the same as 'high-risk group. The 'high risk' was the period during which CPET which was performed. This was a reliable period, since duration between the completion of chemotherapy and the exercise test which was performed, was not at a better, but was a tolerable condition for the participants. We also found that significant difference

Table 2. Differences in the demographic characteristics and clinical features, according to the resting heart rate

\begin{tabular}{lcccc}
\hline \multicolumn{1}{c}{ Parameter } & $\begin{array}{c}\text { Normal } \\
(\mathbf{n = 2 0})\end{array}$ & $\begin{array}{c}\text { Higher } \\
(\mathbf{n = 1 0})\end{array}$ & U & p-value \\
\hline Age (yr) & $51.4 \pm 13.51$ & $50.10 \pm 11.92$ & 91.000 & 0.713 \\
Number of prior intensive chemotherapy & $1.95 \pm 1.10$ & $4.20 \pm 3.01$ & 39.000 & 0.006 \\
ECOG performance status & $0.44 \pm 0.51$ & $0.60 \pm 0.70$ & 81.000 & 0.689 \\
HCT comorbidity index & $0.72 \pm 1.07$ & $0.80 \pm 1.03$ & 83.000 & 0.759 \\
Resting heart rate (bpm) & $87.80 \pm 9.04$ & $107.80 \pm 10.24$ & 0.000 & 0.000 \\
Peak heart rate (bpm) & $159.70 \pm 23.69$ & $165.80 \pm 15.76$ & 80.500 & 0.397 \\
Resting minimal $\mathrm{VO}_{2}(\mathrm{~mL} / \mathrm{kg} / \mathrm{min})$ & $4.33 \pm 2.94$ & $3.96 \pm 1.77$ & 92.500 & 0.746 \\
VO $_{2}$ peak (mL/kg/min) & $24.21 \pm 4.00$ & $20.25 \pm 5.04$ & 56.000 & 0.027 \\
Predicted percent (\%) & $63.99 \pm 13.03$ & $54.32 \pm 12.92$ & 69.000 & 0.183 \\
Resting systolic blood pressure (mmHg) & $123.80 \pm 12.24$ & $115.80 \pm 15.85$ & 71.000 & 0.214 \\
Peak systolic blood pressure (mmHg) & $166.65 \pm 20.23$ & $156.00 \pm 21.62$ & 75.000 & 0.286 \\
Total exercise time (s) & $943.25 \pm 168.89$ & $872.60 \pm 184.72$ & 79.000 & 0.373 \\
Resting double product (bpm·mmHg) & $11,125.20 \pm 1,868.80$ & $12,476.90 \pm 1,946.69$ & 58.000 & 0.067 \\
Peak double product (bpm·mmHg) & $26,688.55 \pm 6,929.30$ & $26,012.60 \pm 5,084.15$ & 91.000 & 0.713 \\
Total body weight (kg) & $67.93 \pm 15.23$ & $67.00 \pm 10.57$ & 99.000 & 0.983 \\
Lean body mass (kg) & $47.88 \pm 10.49$ & $41.04 \pm 10.37$ & 58.500 & 0.067 \\
Fat mass (kg) & $17.31 \pm 7.44$ & $19.38 \pm 7.17$ & 76.000 & 0.307 \\
Skeletal muscle mass in upper extremities (kg) & $5.61 \pm 1.60$ & $4.97 \pm 1.16$ & 76.000 & 0.307 \\
Skeletal muscle mass in lower extremities (kg) & $15.80 \pm 4.07$ & $14.72 \pm 2.90$ & 74.000 & 0.267 \\
Onset to examination (day) & $272.45 \pm 426.18$ & $421.40 \pm 475.55$ & 57.500 & 0.061 \\
\hline
\end{tabular}

Values are presented as mean \pm standard deviation for continuous data.

ECOG, Eastern Cooperative Oncology Group; HCT, hematopoietic cell transplant; $\mathrm{VO}_{2}$ peak, peak oxygen consumption.

p-value was estimated by Mann-Whitney U-test and Kolmogorov-Smirnov test. 


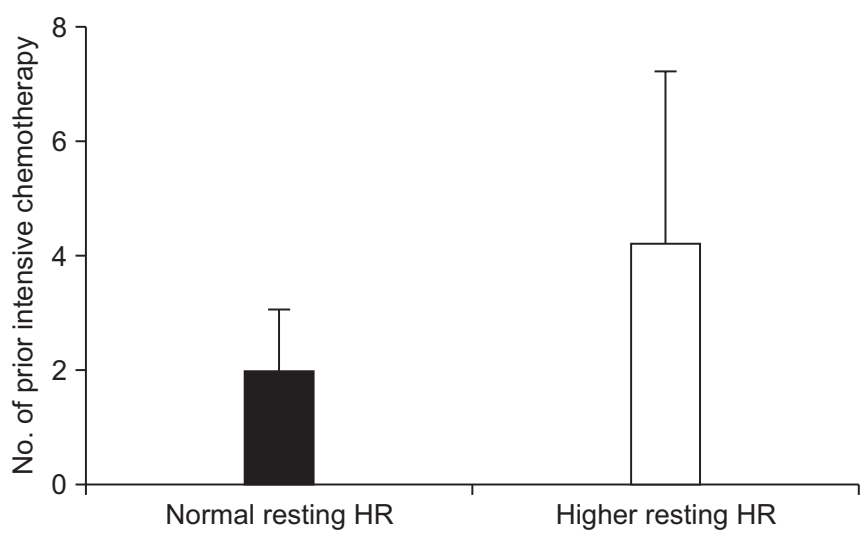

Fig. 3. The mean number of prior intensive chemotherapy. HR, heart rate.

between the resting $\mathrm{HR}$, and the $\mathrm{VO}_{2}$ peak and number of prior intensive chemotherapies. Further studies may reveal whether these two parameters can provide additional information of the functional status, beyond traditional markers.

Originally, we had selected another method to dichotomize the group. As this study was performed retrospectively, we conjectured that the factors which were examined by CPET could make a hypothesis. For example, resting double product, peak double product and $\mathrm{VO}_{2}$ peak could become a dichotomy method to choose reasonably. However, there were not enough researches to refer for a relationship between these factors and any other risk factors. However, if most of the chemotherapy regimens had adverse effects (including cardiotoxicity), we could consider that HR, also known as a basic heart function, might be different amongst participants. If anyone had faster a HR than a normal one at rest, this condition could mean seriously disrupted normal heart function, thereby increasing the risk of stroke, or causing sudden cardiac arrest or death. We were, however, in agreement that this hypothesis might be a serious defect or limitation to dichotomize objectively.

Interestingly, we found significant differences between resting $\mathrm{HR}$ and $\mathrm{VO}_{2}$ peak. Although patients who had tachycardia were not guaranteed against poor comorbidity or medical conditions, the findings were cautiously remarked by clinical decision-making processes. In the higher group, $\mathrm{VO}_{2}$ peak decreased by almost $20 \%$ compared with the normal group. The reductions in $\mathrm{VO}_{2}$ peak observed were somewhat greater than those reported in studies examining the exercise capacity of patients with

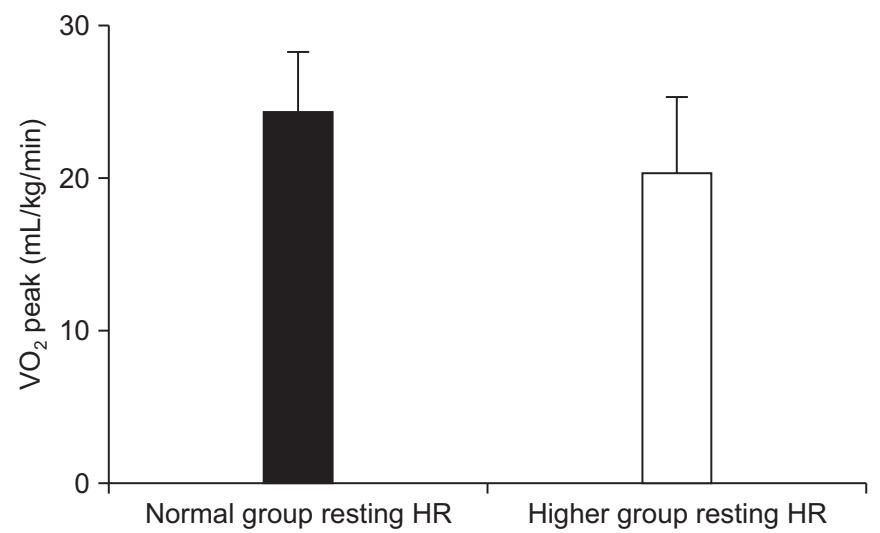

Fig. 4. The mean peak oxygen consumption. HR, heart rate.

other cancers in early stages, but comparable to patients with more advanced or aggressive cancer $[25,26]$.

The number of prior intensive chemotherapy also showed significant difference with resting HR. Although the number of chemotherapy sessions was variable and might be related with the cancer characteristics, we are unable to explain the relationship with the stage of cancer itself. It was thought that more chemotherapy had a greater chance or possibility to damage cardiac tissues. In other words, the accelerated heart condition might also be comparable to other progression of the cancer patients' condition. In addition, among patients with advanced cancers, such as metastatic breast cancer, inoperable none small cell lung cancer, and high-risk or relapsed hematologic malignancies, the $\mathrm{VO}_{2}$ peak was $30 \%$ to $50 \%$ less than expected.

Other suspicious factors, including peak double product, skeletal muscle mass, and lean body mass, were not significantly different with resting HR. Some of these parameters only showed relative difference tendency among the groups, but were not significantly different.

A study by Sadrzadeh Rafie et al. [27] had demonstrated that higher double product reserve was associated with improved survival in patients referred for exercise testing. Double product reserve had greater prognostic power than METs, maximal HR, systolic BP, or HR recovery, and had predicted prognosis independent of traditional clinical risk factors and exercise test responses. In our results, there were no significant difference between resting HR and double product, and only observed by approached significance. Although it was important to note that outcomes associated with impaired double product reserve 
varied, it was the exercise test response that was clearly related to cardiovascular events.

In terms of safety and feasibility, we conducted 30 CPETs with no serious adverse events, and most participants were able to provide maximal efforts. Similarly, Wood et al. [28] demonstrated the safety and feasibility of the CPET and 6MWT in a cohort of patients preparing for stem cell transplantation for a variety of hematologic malignancies. Moreover, our findings have important relevance as a complement to existing tools in clinical practice. Specifically, the quantitative measures of exercise capacity and functional capacity using CPET might serve to more precisely interrogate the physical function conditions of leukemia patients.

CPET and other exercise-based measures are extensively used in non-oncology clinical practice to facilitate treatment eligibility decisions. The only standard clinical application of CPET in oncology is to determine the operability of surgical candidates with lung cancer [29]. As we intended to support the functional status examination of leukemia patients, larger adequately powered prospective studies are required, that systematically evaluate the clinical utility and importance of CPET in allo-SCT.

This study had several limitations. First, was the potential for selection bias because of the transparent purpose of the investigation, and the exclusion of patients with prohibitive comorbid disease. Nevertheless, our proof of concept study of patients with leukemia demonstrates the safety of testing of this nature, and provides data regarding the exercise capacity and functional status of these patients. Second, we did not evaluate the association of initial CPET and diseasefree, recurrence-free or overall survival rate. We only had information on death from any cause; the specific cause of death was not known. Finally, the small number of patients precluded multivariate analyses. Larger prospective trials in homogenous populations will further clarify the utility of CPET procedures in this setting.

In conclusion, we found that CPET in leukemia patients before stem cell transplantation was safe. As CPET presents the parameters showing the cardiopulmonary functions including $\mathrm{VO}_{2}$ peak, double product and exercise capacity, this exercise test would help to predict the physical performance or general condition of the leukemia patients. To use CPET for evaluating cardiac function in leukemia patients would be recommended, along with a parallel echocardiogram.

\section{CONFLICT OF INTEREST}

No potential conflict of interest relevant to this article was reported.

\section{ACKNOWLEDGMENTS}

This study was supported by a grant Translational R\&D Project (No. HI13C-1990-010015) from Chungnam National University Hospital, Republic of Korea.

\section{REFERENCES}

1. Doocey RT, Toze CL, Connors JM, Nevill TJ, Gascoyne $\mathrm{RD}$, Barnett MJ, et al. Allogeneic haematopoietic stem-cell transplantation for relapsed and refractory aggressive histology non-Hodgkin lymphoma. Br J Haematol 2005;131:223-30.

2. Fielding AK, Rowe JM, Richards SM, Buck G, Moorman AV, Durrant IJ, et al. Prospective outcome data on 267 unselected adult patients with Philadelphia chromosome-positive acute lymphoblastic leukemia confirms superiority of allogeneic transplantation over chemotherapy in the pre-imatinib era: results from the International ALL Trial MRC UKALLXII/ ECOG2993. Blood 2009;113:4489-96.

3. Sorror ML, Storer BE, Maloney DG, Sandmaier BM, Martin PJ, Storb R. Outcomes after allogeneic hematopoietic cell transplantation with nonmyeloablative or myeloablative conditioning regimens for treatment of lymphoma and chronic lymphocytic leukemia. Blood 2008;111:446-52.

4. Sureda A, Robinson S, Canals C, Carella AM, Boogaerts MA, Caballero D, et al. Reduced-intensity conditioning compared with conventional allogeneic stem-cell transplantation in relapsed or refractory Hodgkin's lymphoma: an analysis from the Lymphoma Working Party of the European Group for Blood and Marrow Transplantation. J Clin Oncol 2008;26: 455-62.

5. Devergie A, Blaise D, Attal M, Tigaud JD, Jouet JP, Vernant JP, et al. Allogeneic bone marrow transplantation for chronic myeloid leukemia in first chronic phase: a randomized trial of busulfan-cytoxan versus cytoxantotal body irradiation as preparative regimen: a report from the French Society of Bone Marrow Graft (SFGM). 
Blood 1995;85:2263-8.

6. Hartman AR, Williams SF, Dillon JJ. Survival, diseasefree survival and adverse effects of conditioning for allogeneic bone marrow transplantation with busulfan/ cyclophosphamide vs total body irradiation: a metaanalysis. Bone Marrow Transplant 1998;22:439-43.

7. Kroger N, Zabelina T, Kruger W, Renges H, Stute N, Kabisch $\mathrm{H}$, et al. Comparison of total body irradiation vs busulfan in combination with cyclophosphamide as conditioning for unrelated stem cell transplantation in CML patients. Bone Marrow Transplant 2001; 27:349-54.

8. Ringden O, Remberger M, Ruutu T, Nikoskelainen J, Volin L, Vindelov L, et al. Increased risk of chronic graft-versus-host disease, obstructive bronchiolitis, and alopecia with busulfan versus total body irradiation: long-term results of a randomized trial in allogeneic marrow recipients with leukemia. Nordic Bone Marrow Transplantation Group. Blood 1999;93:2196201.

9. Kelsey CR, Horwitz ME, Chino JP, Craciunescu O, Steffey B, Folz RJ, et al. Severe pulmonary toxicity after myeloablative conditioning using total body irradiation: an assessment of risk factors. Int J Radiat Oncol Biol Phys 2011;81:812-8.

10. Jones LW, Courneya KS, Mackey JR, Muss HB, Pituskin EN, Scott JM, et al. Cardiopulmonary function and age-related decline across the breast cancer survivorship continuum. J Clin Oncol 2012;30:2530-7.

11. Jones LW, Hornsby WE, Goetzinger A, Forbes LM, Sherrard EL, Quist M, et al. Prognostic significance of functional capacity and exercise behavior in patients with metastatic non-small cell lung cancer. Lung Cancer 2012;76:248-52.

12. Jones LW, Watson D, Herndon JE 2nd, Eves ND, Haithcock BE, Loewen G, et al. Peak oxygen consumption and long-term all-cause mortality in nonsmall cell lung cancer. Cancer 2010;116:4825-32.

13. Ruden E, Reardon DA, Coan AD, Herndon JE 2nd, Hornsby WE, West M, et al. Exercise behavior, functional capacity, and survival in adults with malignant recurrent glioma. J Clin Oncol 2011;29:2918-23.

14. Acanfora D, De Caprio L, Cuomo S, Papa M, Ferrara N, Leosco D, et al. Diagnostic value of the ratio of recovery systolic blood pressure to peak exercise systolic blood pressure for the detection of coronary artery disease. Circulation 1988;77:1306-10.

15. Myers J, Prakash M, Froelicher V, Do D, Partington S, Atwood JE. Exercise capacity and mortality among men referred for exercise testing. N Engl J Med 2002; 346:793-801.

16. Irving JB, Bruce RA, DeRouen TA. Variations in and significance of systolic pressure during maximal exercise (treadmill) testing. Am J Cardiol 1977;39:841-8.

17. Kitamura K, Jorgensen CR, Gobel FL, Taylor HL, Wang Y. Hemodynamic correlates of myocardial oxygen consumption during upright exercise. J Appl Physiol 1972;32:516-22.

18. Nelson RR, Gobel FL, Jorgensen CR, Wang K, Wang Y, Taylor HL. Hemodynamic predictors of myocardial oxygen consumption during static and dynamic exercise. Circulation 1974;50:1179-89.

19. Kelsey CR, Scott JM, Lane A, Schwitzer E, West MJ, Thomas S, et al. Cardiopulmonary exercise testing prior to myeloablative allo-SCT: a feasibility study. Bone Marrow Transplant 2014;49:1330-6.

20. Scardovi AB, Coletta C, De Maria R, Perna S, Aspromonte N, Feola M, et al. The cardiopulmonary exercise test is safe and reliable in elderly patients with chronic heart failure. J Cardiovasc Med (Hagerstown) 2007;8:608-12.

21. American Thoracic Society; American College of Chest Physicians. ATS/ACCP Statement on cardiopulmonary exercise testing. Am J Respir Crit Care Med 2003;167:211-77.

22. Beaver WL, Wasserman K, Whipp BJ. A new method for detecting anaerobic threshold by gas exchange. J Appl Physiol (1985) 1986;60:2020-7.

23. Fitzgerald MD, Tanaka H, Tran ZV, Seals DR. Agerelated declines in maximal aerobic capacity in regularly exercising vs. sedentary women: a meta-analysis. J Appl Physiol (1985) 1997;83:160-5.

24. Wilson TM, Tanaka H. Meta-analysis of the age-associated decline in maximal aerobic capacity in men: relation to training status. Am J Physiol Heart Circ Physiol 2000;278:H829-34.

25. Myers J, Tan SY, Abella J, Aleti V, Froelicher VF. Comparison of the chronotropic response to exercise and heart rate recovery in predicting cardiovascular mortality. Eur J Cardiovasc Prev Rehabil 2007;14:215-21.

26. Tuchman SA, Lane A, Hornsby WE, Bishop C, Thomas S, Herndon JE 2nd, et al. Quantitative measures of 
physical functioning after autologous hematopoietic stem cell transplantation in multiple myeloma: a feasibility study. Clin Lymphoma Myeloma Leuk 2015;15:103-9.

27. Sadrzadeh Rafie AH, Sungar GW, Dewey FE, Hadley D, Myers J, Froelicher VF. Prognostic value of double product reserve. Eur J Cardiovasc Prev Rehabil 2008; 15:541-7.
28. Wood WA, Deal AM, Reeve BB, Abernethy AP, Basch E, Mitchell SA, et al. Cardiopulmonary fitness in patients undergoing hematopoietic SCT: a pilot study. Bone Marrow Transplant 2013;48:1342-9.

29. Dales RE, Dionne G, Leech JA, Lunau M, Schweitzer I. Preoperative prediction of pulmonary complications following thoracic surgery. Chest 1993;104:155-9. 